\title{
T cells presenting viral antigens or autoantigens induce cytotoxic T cell anergy
}

\author{
Nathalie E. Blachère, ${ }^{1,2}$ Dana E. Orange, ${ }^{1,3,4}$ Emily C. Gantman, ${ }^{1,5}$ Bianca D. Santomasso, ${ }^{1,6}$ \\ Graeme C. Couture, ${ }^{1}$ Teresa Ramirez-Montagut,, ${ }^{1,7}$ John Fak, ${ }^{1}$ Kevin J. O'Donovan,, ${ }^{1,8}$ Zhong Ru, ${ }^{1}$ \\ Salina Parveen, ${ }^{1}$ Mayu O. Frank,, ${ }^{1,4}$ Michael J. Moore, ${ }^{1,9}$ and Robert B. Darnell1,2,4 \\ 'Laboratory of Molecular Neuro-Oncology, The Rockefeller University, New York, New York, USA. ${ }^{2}$ Howard Hughes Medical \\ Institute, New York, New York, USA. ${ }^{3}$ Division of Rheumatology, Hospital for Special Surgery, New York, New York, USA. \\ ${ }^{4}$ New York Genome Center, New York, New York, USA. ${ }^{5}$ CHDI Management/CHDI Foundation, New York, New York, USA. \\ ${ }^{6}$ Memorial Sloan-Kettering Cancer Center, New York, New York, USA. 'Cenentech, Inc., South San Francisco, California, \\ USA. ${ }^{8}$ Department of Chemistry and Life Sciences, United States Military Academy, West Point, New York, USA. \\ ${ }^{9}$ Regeneron Pharmaceuticals, Tarrytown, New York, USA.
}

In the course of modeling the naturally occurring tumor immunity seen in patients with paraneoplastic cerebellar degeneration (PCD), we discovered an unexpectedly high threshold for breaking CD8+ cytotoxic T cell (CTL) tolerance to the PCD autoantigen, CDR2. While CDR2 expression was previously found to be strictly restricted to immune-privileged cells (cerebellum, testes, and tumors), unexpectedly we have found that T cells also express CDR2. This expression underlies inhibition of CTL activation; CTLs that respond to epithelial cells expressing CDR2 fail to respond to $T$ cells expressing CDR2. This was a general phenomenon, as T cells presenting influenza (flu) antigen also fail to activate otherwise potent flu-specific CTLs either in vitro or in vivo. Moreover, transfer of flu peptide-pulsed T cells into flu-infected mice inhibits endogenous flu-specific CTLs. Our finding that T cells serve as a site of immune privilege, inhibiting effector CTL function, uncovers an autorepressive loop with general biologic and clinical relevance.

Authorship note: N.E. Blachère and D.E. Orange contributed equally to this work.

Conflict of interest: The authors have declared that no conflict of interest exists.

Submitted: July 10, 2017 Accepted: September 25, 2017 Published: November 2, 2017

\section{Reference information:} JCI Insight. 2017;2(21):e96173. https://doi.org/10.1172/jci. insight. 96173

\section{Introduction}

Paraneoplastic cerebellar degeneration (PCD) is a rare type of paraneoplastic neurologic disease (PND) that can arise when patients develop tumors expressing cerebellar degeneration-related protein 2 (CDR2). CDR2 is a cytoplasmic protein that is robustly expressed in Purkinje cells of the cerebellum. Patients develop neurologic symptoms when tumor cells expressing CDR2 trigger a CDR2-specific immune response that crosses the blood-brain barrier, resulting in profound cerebellar dysfunction. The hallmark of the disease is the production of high-titer antibodies against CDR2, also known as Yo antibodies, and circulating effector cytotoxic $\mathrm{T}$ cells in the blood and cerebral spinal fluid (CSF) that produce IFN- $\gamma$ in response to CDR2 (1-3). Interestingly, this CDR2-specific immune response also effectively lyses target cells in an HLA-restricted manner and recognizes tumor cells $(1,2,4)$, resulting in occult or limited-stage tumors and relative tumor immunity (5).

PCD is extraordinarily rare despite the fact that approximately $56 \%$ of ovarian tumors and approximately $22 \%$ of breast tumors ectopically express CDR2 $(5,6)$. Given that expression is normally limited to the Purkinje cells of the cerebellum, it stands to reason that the immune system should be relatively ignorant to CDR2, facilitating responses to this tumor antigen. However, a study of 553 serum samples of PND patients discovered that no patients with primary antibodies against any of the other PND antigens harbored additional antibodies against CDR2 (PCA-1) (7), though 19\% to 50\% of patients with PND harbored coexisting antibodies against other intracellular neuronal antigens. This suggests there is an increased threshold for breaking tolerance to CDR2, relative to other PND antigens. Understanding the mechanism of this clinical observation could uncover insights about tolerance to tumors and immune responses more generally. Here we report the surprising finding that T cells themselves express CDR2 and that the identity of the cell presenting CDR2 has a profound effect on effector CTL responses; the threshold for breaking tolerance to CDR2 is higher when it is expressed in T cells than in the CNS. 
A

Cdr2 Knockout
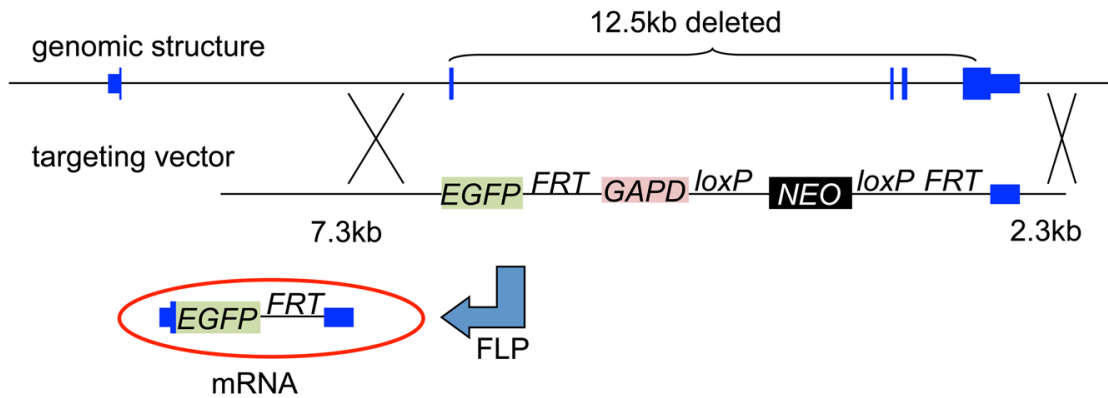

B

Cdr2



3'UTR

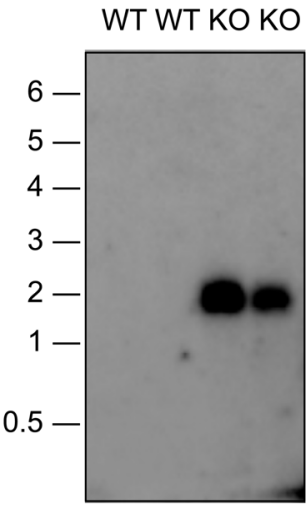

3'UTR
C

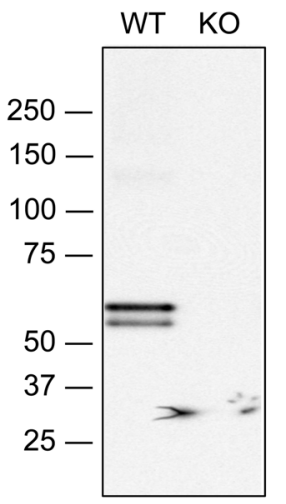

Figure 1. Construct and strategy for generating and validating Cdr2-KO mice. (A) Schematic representation of the $C d r 2$ locus before and after homologous recombination with the targeting vector, as well as after FLP recombination. The elements in the final targeting vector in order ( $5^{\prime}$ to $3^{\prime}$ ) were: $7.3 \mathrm{~kb}$ of $C d r 2$ intron 1 and the first 14 bp of exon 2 (shown in blue); EGFP (shown in green); an FRT site; $1.5 \mathrm{~kb}$ from the human $C A P D$ gene containing its $3^{\prime}$ UTR and $1.3 \mathrm{~kb}$ of $3^{\prime}$ flanking sequence (shown in maroon); a neomycin resistance cassette (shown in black) flanked by loxP sites; a second $F R T$ site; and $2.3 \mathrm{~kb}$ of the $C d r 2$ gene corresponding to the $0.9 \mathrm{~kb}$ Cdr2 $3^{\prime}$ UTR and 1.4 $\mathrm{kb}$ of $3^{\prime}$ flanking sequence. (B) Northern blot of 13th generation Cdr2-KO and WT mouse cerebellum. RNA was hybridized with probes for Cdr2, EGFP, and the 3'UTR of Cdr2. The blot was normalized by loading equal amounts of total RNA in each lane. (c) Western blot of Cdr2-KO and WT cerebellum. Cerebellar lysates were immunoprecipitated with a paraneoplastic cerebellar degeneration patient antibody and resolved by SDS-PACE and probed with an anti-CDR2 antibody.

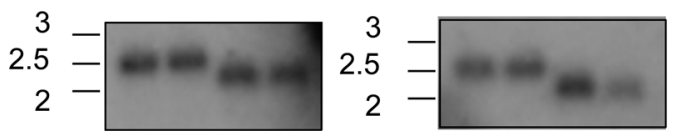

\section{Results}

Generation of Cdr2-knockout mice. A fundamental goal of studying PCD patients is to understand mechanisms underlying naturally occurring tumor immunity and autoimmune brain disease. In initial attempts to model tumor immunity to CDR2 in mice, we observed poor immune responses to CDR2 vaccination. To test whether this was related to development of tolerance to endogenous CDR2-derived antigens, we generated $C d r 2$-knockout ( $C d r 2-\mathrm{KO})$ mice for immunizations. Mice were generated using homologous recombination with a targeting vector containing $E G F P$ (Figure $1 \mathrm{~A}$ ) replacing $12.5 \mathrm{~kb}$ of the $C d r 2$ gene (including all of the $C d r 2$ coding region after the first $14 \mathrm{bp}$ of exon 2) with EGFP and an intact Cdr2 3'UTR; the absence of $C d r 2$ expression and presence of EGFP expression was confirmed by Northern blot (Figure 1B) and Western blot (Figure 1C).

CDR2 expression in wild-type mice limits the generation of humoral and cellular immune responses to CDR2. Cdr2-KO mice mounted high-titer $(>1: 1,000)$ IgG responses to CDR2 vaccination, but wild-type (WT) mice did not, even when vaccinated with considerable doses of antigen (Figure 2A). Cdr2-KO mice were competent to produce antibodies against a control antigen ( $\beta$-gal) (Figure 2A).

We also assayed $\mathrm{T}$ cell responses in WT and Cdr2-KO mice. We first sought to identify the naturally processed and immunodominant $\mathrm{MHCI}$ and $\mathrm{MHCII}$ epitopes in $\mathrm{H}-2^{\mathrm{b}}$ mice. We isolated $\mathrm{CD}^{+} \mathrm{T}$ cells from Cdr2-KO mice shown to have CDR2-specific antibodies in Figure 2A and in vitro stimulated the cells with MHCII $\left(\mathrm{H}-2 \mathrm{~A}^{\mathrm{b}}\right)$ predicted binding peptides. We found that CDR2-170 and -172 are naturally processed epitopes of CDR2 (Figure 2B). We next challenged Cdr2-KO and WT mice with adenovirus expressing CDR2 (AdV-CDR2) and adenovirus expressing $\beta$-gal (AdV- $\beta$-gal). WT CD4 ${ }^{+} \mathrm{T}$ cells produced poor responses to both CDR2-170 and -172 compared with $\mathrm{CD}^{+} \mathrm{T}$ cells from $\mathrm{KO}$ mice (Figure $2 \mathrm{C}$ ). To identify MHCI epitopes, Cdr2-KO or WT mice were immunized with AdV-CDR2. CDR2-120 peptide-pulsed RMA-S cells 
A



B

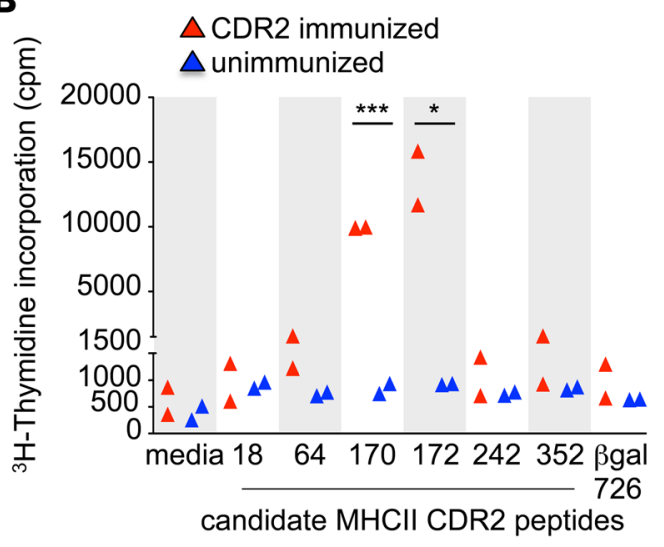

D

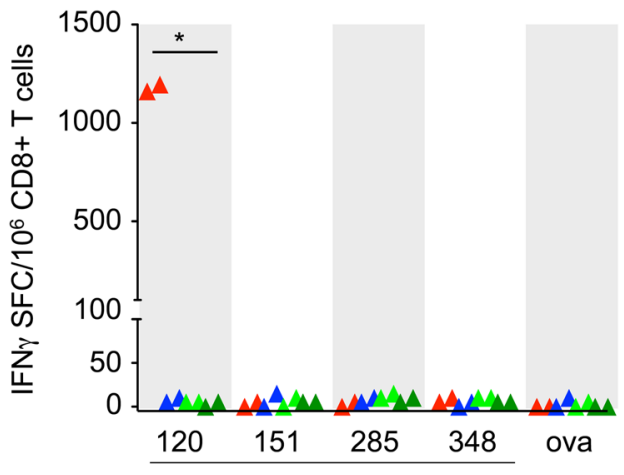

candidate $\mathrm{MHCl} \mathrm{CDR} 2$ peptides

\section{$\beta$ gal SDS-PAGE}

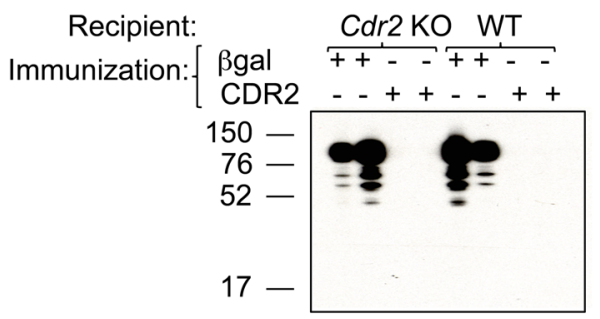

C

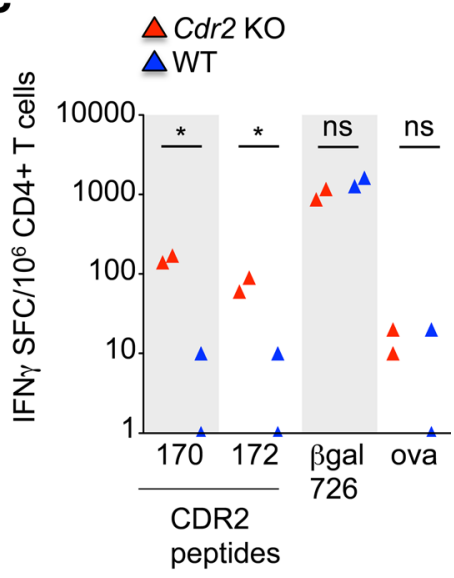

Immunization/Recipient:

$\triangle \mathrm{AdV}-\mathrm{CDR} 2 / \mathrm{KO}$

$\triangle \mathrm{AdV}-\mathrm{CDR} 2 / \mathrm{WT}$

$\triangle A d V$-trk/KO

$\triangle A d V$-trk/WT
Figure 2. CDR2 expression in WT mice limits the generation of humoral and cellular immune responses to CDR2. (A) Western blots of serum from Cdr2-KO or WT mice immunized with $\beta$-gal or CDR2 and tested for the presence of IgC 21 days later. Left panel: CDR2 resolved by SDS-PACE. Right panel: $\beta$-Gal resolved by SDS-PAGE. One experiment is shown and is representative of 2 experiments. (B) $C D 4^{+} \mathrm{T}$ cell proliferation as measured by ${ }^{3} \mathrm{H}$-thymidine incorporation from unimmunized or CDR2immunized $\mathrm{Cdr2-KO}$ mice stimulated with candidate CDR2 peptide-pulsed Cdr2-KO splenocytes. Each triangle represents $\mathrm{CD}^{+} \mathrm{T}$ cells from 2 mice pooled and plated in triplicate wells and is representative of 3 experiments. (C) IFN- $\gamma$ ELISPOT assay of CD4 ${ }^{+} \mathrm{T}$ cells from Cdr2-KO $(n=2)$ or WT hosts ( $n$ $=2$ ) immunized with both AdV- $\beta$-gal and AdV-CDR2 and cultured with Cdr2-KO splenocytes pulsed with various peptides. Each triangle is the mean of triplicate wells of $\mathrm{CD}^{+} \mathrm{T}$ cells from 1 mouse and is representative of 3 experiments. (D) IFN- $\gamma$ ELISPOT assay of CD8 ${ }^{+} T$ cells from Cdr2-KO or WT hosts immunized with AdV-Trk or AdVCDR2. Each triangle represents CD8 ${ }^{+} \mathrm{T}$ cells from 2 mice pooled and plated in triplicate wells and is representative of 3 experiments. ${ }^{*} P<0.05,{ }^{* *} P<0.001$; ns, statistically not significant as calculated using unpaired Student's $t$ test. AdV, adenovirus; Cpm, counts per minute; SFC, spot-forming cells; OVA, ovalbumin peptide.

elicited the highest level of IFN- $\gamma$ production in Cdr2-KO hosts, and was not recognized in WT hosts (Figure 2D). Together, these data reveal a defect in antibody $\mathrm{CD} 4^{+}$and $\mathrm{CD} 8^{+} \mathrm{T}$ cell immune responses to endogenous CDR2 in WT hosts and that CDR2 tolerance is lacking in mice that do not express the CDR2 protein.

$C D R 2$ expression is more tolerogenic when expressed by $T$ cells than by neurons. To further explore the mechanism of tolerance to CDR2, we generated bone marrow chimeras and tested them for CDR2-specific CTL responses. $C d r 2-\mathrm{WT}$ or -KO mice were transplanted with $C d r 2-\mathrm{WT}$ or -KO bone marrow cells, and $\mathrm{T}$ cell responses were assessed 14 days after immunization with AdV-CDR2 by IFN- $\gamma$ ELISPOT assay. $\mathrm{CD}^{+} \mathrm{T}$ cells isolated from $\mathrm{KO}$ mice transplanted with $\mathrm{Cdr} 2$-KO bone marrow produced IFN- $\gamma$ in response to CDR2120-pulsed RMA-S cells directly ex vivo (Figure 3A) and after in vitro stimulation (Figure 3B). CD8 ${ }^{+} \mathrm{T}$ cells isolated from WT mice transplanted with $C d r 2-\mathrm{KO}$ bone marrow did not produce IFN- $\gamma$ in response to CDR2-120 directly ex vivo (Figure 3A), but were able to be activated after in vitro stimulation (Figure 3B). In contrast, $\mathrm{CD} 8^{+} \mathrm{T}$ cells isolated from $\mathrm{Cdr2}-\mathrm{KO}$ mice transplanted with $\mathrm{WT}$ bone marrow were unable to respond to CDR2 either directly ex vivo or with in vitro stimulation (Figure 3, A and B). Nonhematopoietic, radio-resistant cell (such as Purkinje cell) expression of CDR2 leads to partial tolerance to CDR2, as CDR2specific $\mathrm{T}$ cell responses in this chimera $(\mathrm{KO} \rightarrow \mathrm{WT})$ could be eventually demonstrated after in vitro stimulation. Interestingly, the most profound tolerance was seen in the Cdr2-KO hosts receiving WT bone marrow. In this scenario (WT $\rightarrow \mathrm{KO}$ ), CTL responses to CDR2 could not be recovered, even with subsequent in vitro 
A Direct ex vivo:
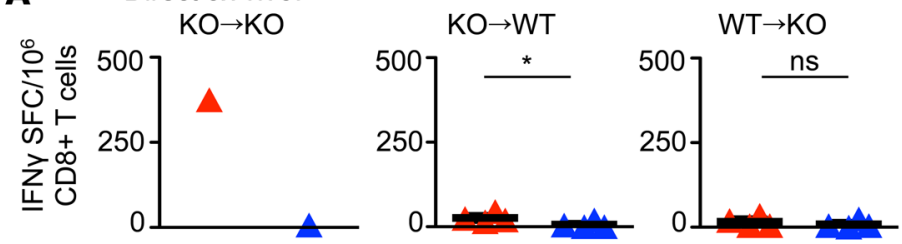

B
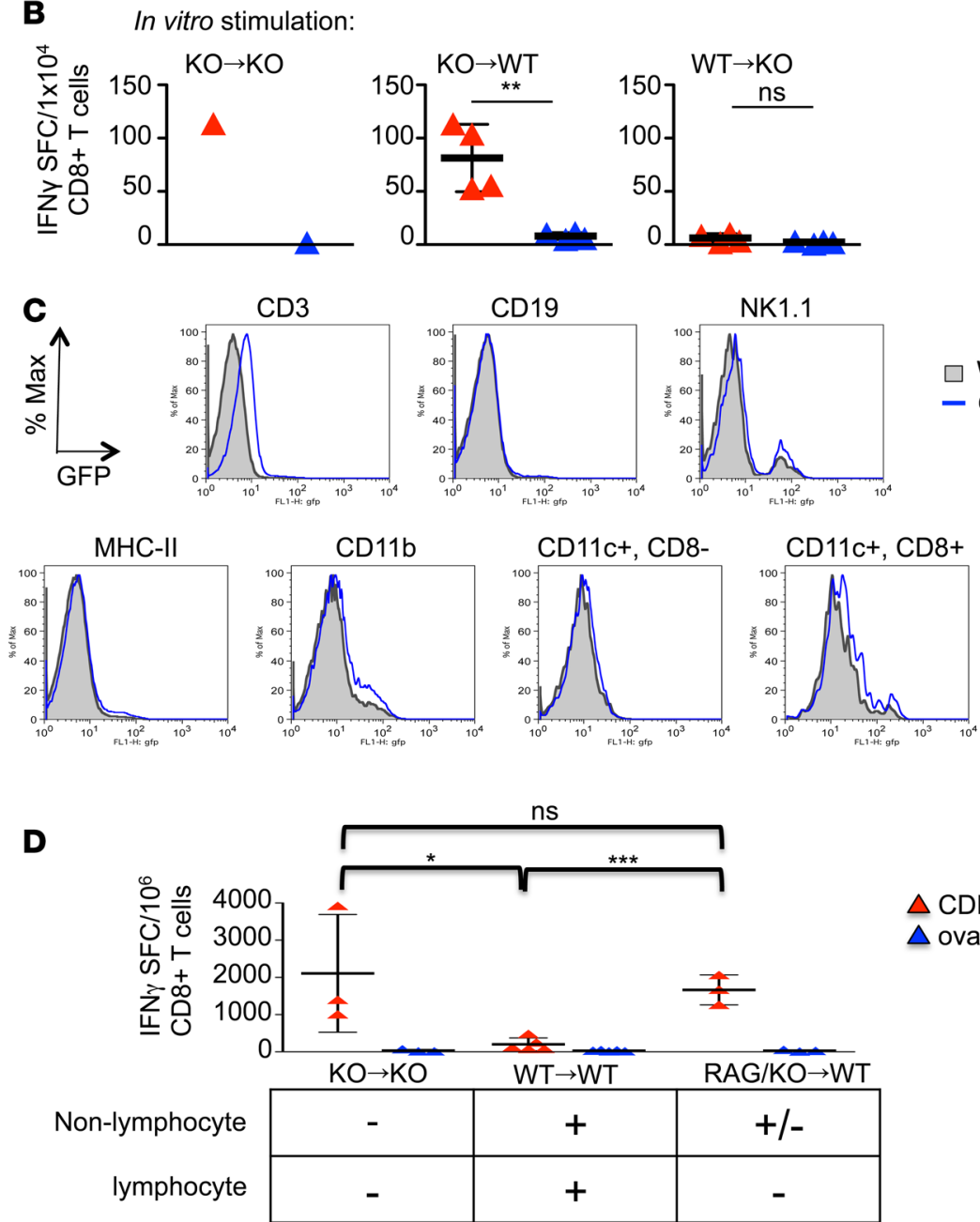

$\square$ WT

- Cdr2 KO

$\triangle \mathrm{CDR} 2-120$

$\triangle$ ova

$\triangle \mathrm{CDR} 2-120$

$\triangle$ ova
Figure 3. T cell expression of CDR2 is sufficient to confer tolerance. IFN- $\gamma$ ELISPOTs of CD8 ${ }^{+}$

$T$ cells from bone marrow (BM) chimera mice 14 days after immunization with adenovirus expressing CDR2 (AdV-CDR2) and cultured with RMA-S cells pulsed with either OVA or CDR2-120 peptide immediately ex vivo (A) and after 7 days of splenocyte in vitro stimulation (B). Each triangle represents the mean of triplicate wells and the bar with error bars represents the mean and standard deviations of mice in that group. These data are representative of 2 experiments. $\mathrm{KO} \rightarrow \mathrm{KO}$ indicates $\mathrm{Cdr2-KO} \mathrm{BM}$ donor cells transplanted into $C d r 2-K O$ host mice $(n=1), \mathrm{KO} \rightarrow \mathrm{WT}(n=4)$ indicates $\mathrm{Cdr2-KO} \mathrm{BM}$ donor cells transplanted into WT host mice, and WT $\rightarrow \mathrm{KO}(n=4)$ indicates WT BM donor cells transplanted into Cdr2-KO host mice. (C) Flow cytometry of hematopoietic cells from WT or Cdr2-KO mice. The EGFP gene replaces the $C d r 2$ gene in $C d r 2-K O$ mice. Gray filled $=\mathrm{WT}$, blue line $=C d r 2-\mathrm{KO}$. One experiment is shown and is representative of 5 experiments. (D) BM chimeras were established as in $\mathbf{A}$ and $\mathbf{B}$ with the addition of RAC/Cdr2-KO $\rightarrow$ WT $(n=3)$ indicating a mix of 50:50 Rag1-KO and Cdr2-KO BM cells transplanted into WT mice. Fourteen days after immunization, splenocytes were stimulated in vitro for 7 days with CDR2-120 peptide and $C D 8^{+} T$ cells were tested for response to RMA-S cells pulsed with either OVA or CDR2120 peptide by IFN- $\gamma$ ELISPOT in triplicate wells. Results presented are 1 of 2 experiments. Each triangle represents the mean of triplicate wells and the bar with error bars represents the mean and standard deviations of mice in that group. These data are representative of 2 experiments. $\mathrm{KO} \rightarrow \mathrm{KO}(n=3), \mathrm{WT} \rightarrow \mathrm{WT}(n=5), \mathrm{RAG} / \mathrm{KO} \rightarrow \mathrm{WT}$ $(n=3) .{ }^{*} P<0.05,{ }^{* *} P<0.01,{ }^{* * *} P<0.001 ; \mathrm{ns}$, statistically not significant as calculated using unpaired Student's $t$ test. SFC, spot-forming cells; OVA, ovalbumin peptide.

stimulation. Taken together, these results suggest that CDR2 is expressed by a hematopoietic cell and that there are distinct thresholds of tolerance to CDR2, depending on its site of expression.

To address whether some hematopoietic cells express CDR2, we tested hematopoietic lineages for CDR2 expression, using knocked-in EGFP from $C d r 2-\mathrm{KO}$ mice as a surrogate marker. $\mathrm{CD}^{+} \mathrm{T}$ cells expressed the CDR2 marker, as measured by a clear shift in EGFP, whereas CD19, NK cells, $\mathrm{MHCII}^{+}$, and CD11c subsets did not (Figure 3C). A small population of CD11b+ cells expressed low levels of CDR2. These either represent phagocytic cells that have taken up dying $\mathrm{T}$ cells or a subpopulation of $\mathrm{CD}_{1} 1 \mathrm{~b}^{+}$cells that express low levels of CDR2. To assess which of the hematopoietic cells mediate the robust tolerance seen in Figure 3, A and B, we compared CDR2-specific CTL responses in mice that were transplanted with Cdr2-KO bone marrow (positive control), WT bone marrow (negative control), or a mixture of recombinase-activating gene 1-KO (Rag1-KO) bone marrow and Cdr2-KO bone marrow. In this latter scenario, all lymphocytes are $C d r 2-$ $\mathrm{KO}$, while the nonlymphocytic hematopoietic cells are a mix of Cdr2-KO and Cdr2-WT. CDR2 vaccination of these mice, lacking $C d r 2$ specifically in lymphocytes, produced CTL responses that are not significantly different from $C d r 2-\mathrm{KO}$ mice transplanted with $C d r 2-\mathrm{KO}$ bone marrow (Figure 3D). Taking these results 
A

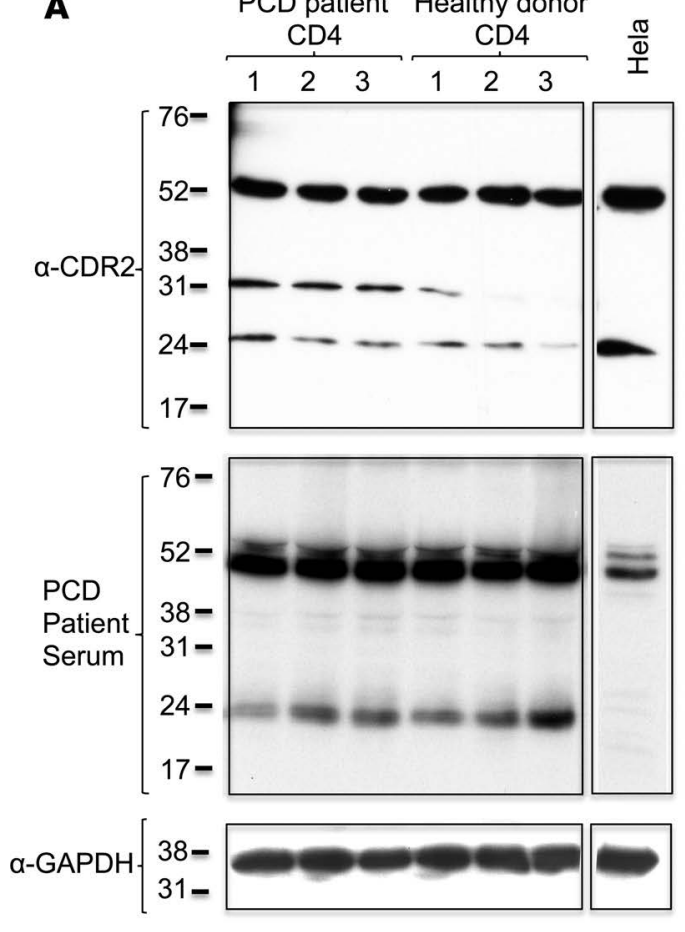

B
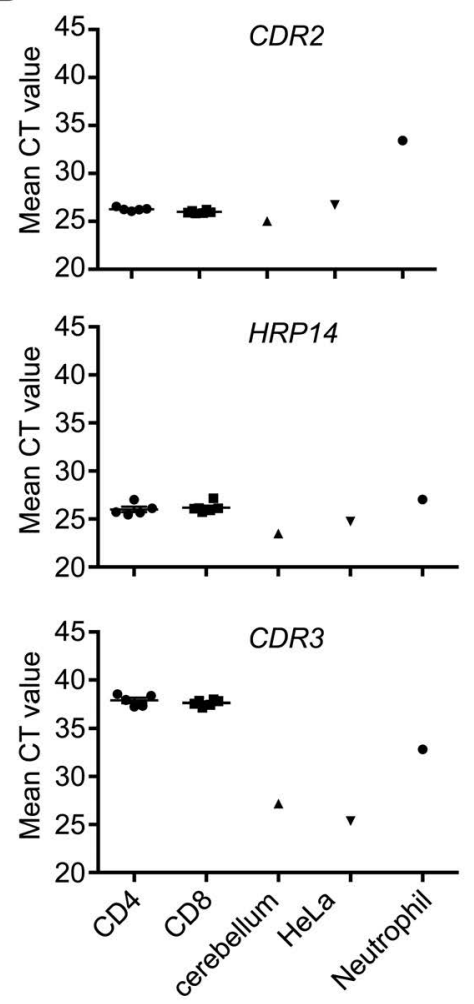

Monocyte
Figure 4. Human T cells express CDR2 protein. (A) Western blot of CD4 ${ }^{+} \mathrm{T}$ cells from 3 paraneoplastic cerebellar degeneration (PCD) patients, 3 healthy donors, and HeLa cells probed with antiCDR2 antibody (top panel). Membrane was stripped and reprobed first with PCD patient sera diluted 1:1,000 (middle panel) and then with anti-GAPDH antibody (lower panel). (B) qPCR of CDR3, CDR2, and HRP14 from healthy donor CD4 ${ }^{+} \mathrm{T}$ cells $(n=5)$, CD8 $^{+}$T cells $(n=6)$, human cerebellum $(n=1)$, HeLa cells $(n=1)$, or neutrophils $(n=1)$. HRP14 RNA expression is presented as a housekeeping gene for the various cell and tissue types. Mean cycle time values of technical triplicates are presented. One experiment is shown and is representative of 3 experiments. (C) Absolute white blood cell, lymphocyte, and monocyte counts from 11 ovarian cancer patients with PCD drawn at the time of recent worsening of neurologic symptoms. All had high-titer $(>1: 1,000)$ antibodies against CDR2. Normal ranges are represented by the shaded area. Each bar represents the mean and error bars are standard deviations.
C

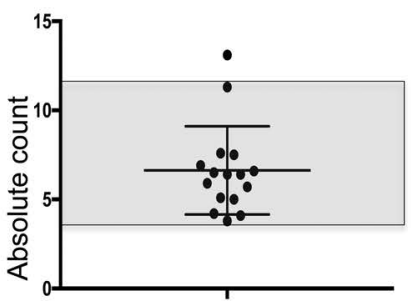

Lymphocyte

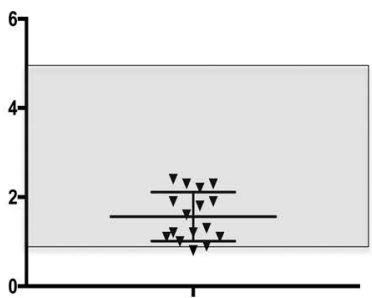

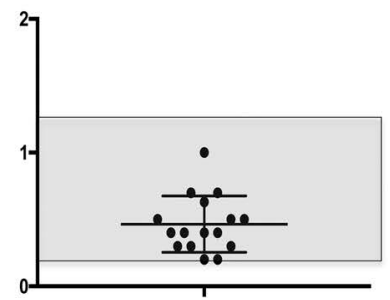

together, we conclude that CDR2-expressing $\mathrm{CD}^{+} \mathrm{T}$ cells are sufficient to confer tolerance to CDR2.

Human T cells also express CDR2 but are not targeted in patients with PCD. To directly test for CDR2 expression in hematopoietic cells, we assessed CDR2 expression by Western blot of human $\mathrm{CD} 4^{+} \mathrm{T}$ cells. We observed that these cells express readily detectable levels of CDR2, as assessed by both a monoclonal antibody against CDR2 and PCD patient serum (Figure 4A). The results were supported by RNA analyses; CDR2 RNA was robustly expressed, with low mean cycle time values, in $\mathrm{CD} 4^{+}$and $\mathrm{CD} 8^{+} \mathrm{T}$ cells. These values were comparable to those seen in the positive control tissue types, cerebellum and HeLa cells. CDR2 cycle time was much higher in neutrophils, indicating that the expression in this cell type is lower than in $\mathrm{T}$ cells or cerebellum, but unlikely to be nonexistent (Figure 4B). To test whether the Western blot signal could be due to antibody cross reactivity with the CDR2 paralog, CDR3, we investigated RNA expression using PCR primers specific for $C D R 3$ in human T cells. Quantitative PCR (qPCR) demonstrated that $C D R 3$ mRNA is robustly expressed in cerebellar lysate and HeLa cells but undetectable in $\mathrm{CD} 8^{+}$and $\mathrm{CD} 4^{+} \mathrm{T}$ cells (Figure 4B). Taken together, these results demonstrate that CDR2 is expressed in human T cells.

Patients with PCD and clear evidence of autoimmunity to CDR2 are not known to suffer from lymphopenia, prompting us to assess white blood cell counts from our previously described (8) cohort of 11 patients with high-titer antibodies against CDR2 and recent neurologic decline (suggesting acute flare of disease). We found that PCD patients had no leukopenia or lymphopenia in the course of 16 flares among 11 patients (Figure 4C). We conclude that patients with PCD and autoimmune targeting of CDR2 suffer neurologic decline without $\mathrm{T}$ cell depletion, consistent with in vivo tolerance to $\mathrm{T}$ cell CDR2 expression in humans. 


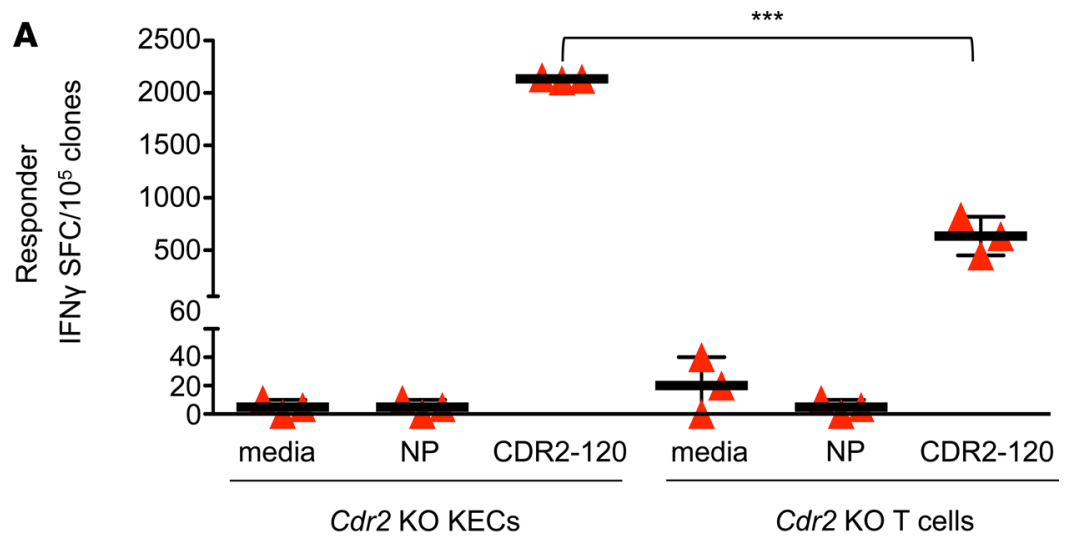

Stimulators

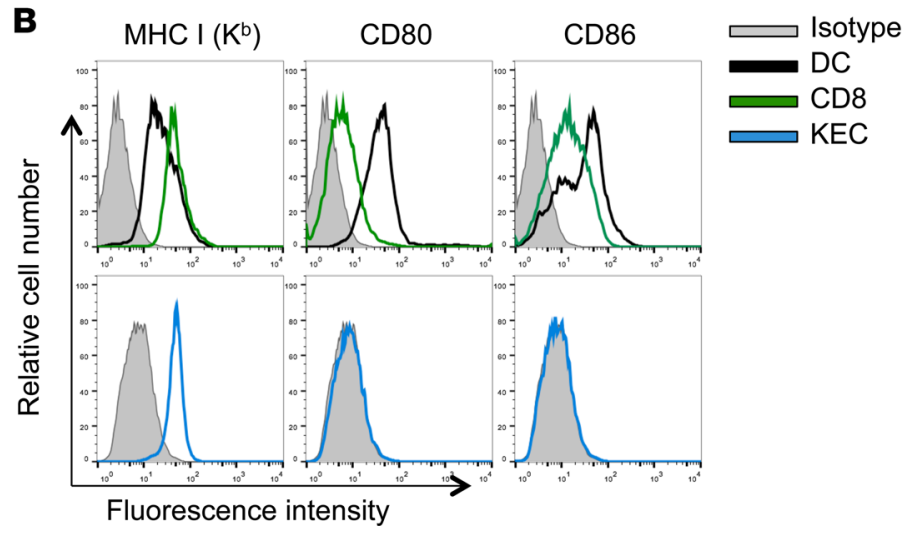

Figure 5. T cell presentation of CDR2 does not activate CDR2-specific $T$ cell clones. (A) IFN- $\gamma$ ELISPOT assay of CDR2-specific T cell clones cultured with Cdr2-KO kidney epithelial cells (KECs) or T cells pulsed with various peptides. NP indicates pulsed with irrelevant control influenza peptide and CDR2-120 indicates pulsed with cognate peptide. Each bar represents the mean of triplicate wells and error bars are standard deviations. (B) Surface staining of $\mathrm{MHCl}$ and costimulatory molecules in DCs (black line), live T cells (green line), KECs (blue line), and isotype control (shaded). These data are representative of 3 experiments. ${ }^{* *} P<0.001$, as calculated using unpaired Student's $t$ test. SFC, spot-forming cells.

Effector CTLs produce less IFN- $\gamma$ in response to antigen presented by $T$ cells compared with KECs. To explore whether $\mathrm{T}$ cell tolerance to CDR2 is due to differences in antigen presentation by $\mathrm{T}$ cells, we compared responses of murine effector CTL clones to either Cdr2KO kidney epithelial cells (KECs) or Cdr2-KO T cells pulsed with CDR2-120 peptide or negative control influenza nuclear protein (NP) peptide or media. CTLs produced robust IFN- $\gamma$ responses to CDR2-120-pulsed KECs (Figure 5A). However, CTL clones produced significantly less robust IFN- $\gamma$ responses to CDR2 peptide-pulsed KO T cells (Figure 5A). This result could not be attributed to differences in expression of MHCI or costimulatory molecules, since we observed that $\mathrm{CD}^{+} \mathrm{T}$ cells expressed these at levels at least as robust as those in KECs or dendritic cells (DCs; Figures 5B). We conclude that despite expression of MHCI and costimulatory molecules, $\mathrm{T}$ cell presentation of CDR2 peptide is less effective than KEC-mediated activation of effector CTL IFN- $\gamma$ responses.

$T$ cell antigen presentation of virus also limits effector CTL responses. To test whether the lack of effector CTL activation in our system could be an idiosyncratic feature of the CDR2 protein or is generalizable to other antigens, we assessed $\mathrm{T}$ cell responses to $\mathrm{T}$ cells presenting viral antigens, using the well-characterized flu system. We challenged mice with live flu virus and transferred NP or OVA-pulsed CD8 ${ }^{+} \mathrm{T}$ cells and measured expansion of NP-specific host $\mathrm{CD}^{+} \mathrm{T}$ cells by tetramer assay. Peripheral blood from mice infused with NP-pulsed $\mathrm{CD}^{+} \mathrm{T}$ cells contained significantly fewer NP-specific $\mathrm{CD} 8^{+} \mathrm{T}$ cells than those that received OVA-pulsed CD8 $\mathrm{T}$ cells (Figure 6A). As a control, we found no difference in transferred NP or OVA-pulsed CD8 ${ }^{+} \mathrm{T}$ cells recoverable at day 8 (data not shown). While intravenous injections of free peptide at high doses $(0.1 \mathrm{mg})$ can limit CTL responses in vivo (9), the CD8 $8^{+} \mathrm{T}$ cells in this experiment were pulsed with much lower amounts $(1 \mu \mathrm{M})$, making it unlikely that low amounts of dissociating free peptide could account for these results. Instead, we attribute the decrease in NP-specific CD8 ${ }^{+} \mathrm{T}$ cells to the transfer of NP-pulsed CD8 ${ }^{+} \mathrm{T}$ cells.

To test the effect of $\mathrm{T}$ cell presentation of flu peptides in vitro, we measured NP-specific effector CTL responses to NP- or OVA-pulsed and irradiated DCs, KECs, $\mathrm{CD}^{+}$, or $\mathrm{CD}^{+}$cells. While NP-specific effector CTLs robustly produce IFN- $\gamma$ in response to NP-pulsed DCs and even KECs, which are not professional antigen-presenting cells, they produce significantly less IFN- $\gamma$ in response to NP-pulsed CD8 ${ }^{+}$and $\mathrm{CD}^{+}$ lymphocytes (Figure 6B). Addition of IL-2 rescued the ability of $\mathrm{CD}^{+}$lymphocytes to activate CTL IFN- $\gamma$ production in an antigen-specific manner (Figure 6C). Taken together, these data indicate that antigen presentation by $\mathrm{T}$ cells attenuates flu-specific CTL expansion in vivo and induces flu-specific effector CTL anergy in vitro that can be recovered with IL-2.

\section{Discussion}

PNDs provide a unique window to examine mechanisms of immunity and tolerance. Here, we describe our discovery that CTLs capable of responding to a variety of cell types presenting the CDR2 PND antigen do 
A

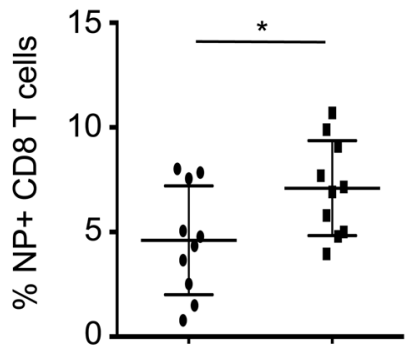

Host transferred with: CD8/NP CD8/ova
D

IN VIVO

$\mathrm{T}$-T interaction

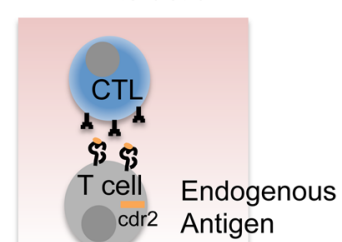

Antigen
B

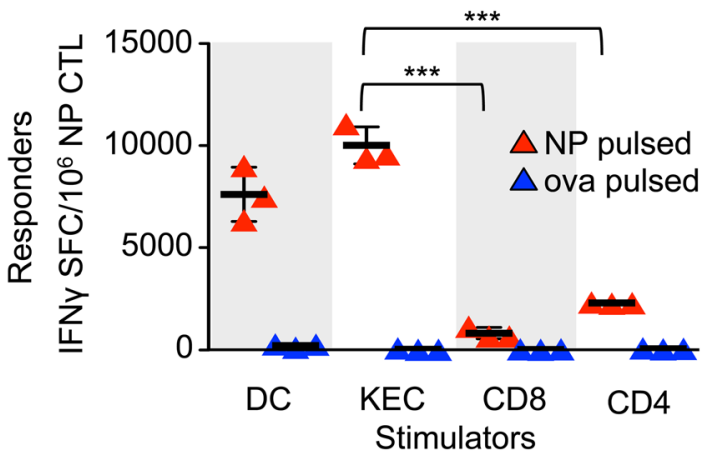

C

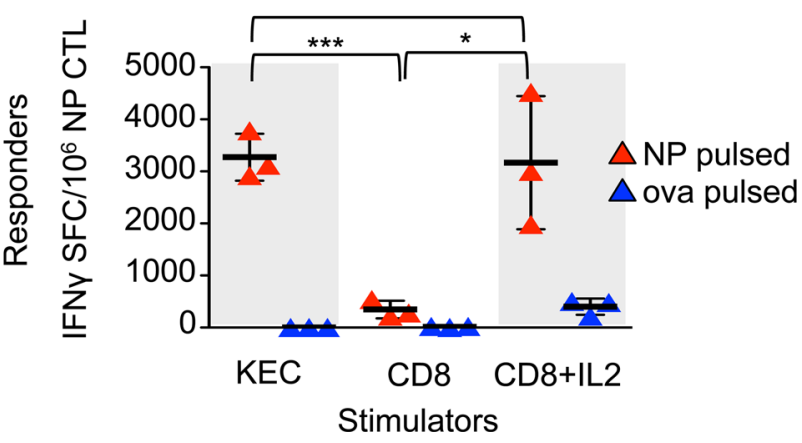

Figure 6. T cell antigen presentation induces effector CTL split anergy. (A) Flow cytometry of circulating CD45.2 $2^{+} \mathrm{NP}-$ specific tetramer ${ }^{+} \mathrm{CD} 8^{+} \mathrm{T}$ cells in a flu-infected host transferred with either NP-pulsed $(n=10)$ or OVA-pulsed $(n=10) \operatorname{CD} 45.1^{+} \operatorname{CD}^{+}$T cells. Each bar represents the mean and error bars are standard deviations. These data are representative of 2 experiments. (B) IFN- $\gamma$ ELISPOT assay of NP-specific effector CTLs cultured with DCs or kidney epithelial cells (KECs) (stimulator to effector ratio of 1:30), or $C D 8^{+}$or $C D 4^{+} T$ cells (stimulator to effector ratio of 1:1). Each bar represents the mean of triplicate wells and error bars are standard deviations. These data are representative of 2 experiments. (C) IFN- $\gamma$ ELISPOT assay of NP-specific effector CTLs cultured with KECs (stimulator to effector ratio of 1:30), CD8 ${ }^{+}$T cells (stimulator to effector ratio of 1:1), or CD8 ${ }^{+}$T cells plus IL-2. Stimulator cells were pulsed with either NP or OVA peptide. Each bar represents the mean of triplicate wells and error bars are standard deviations. These data are representative of 2 experiments. ${ }^{*} P<0.05,{ }^{* *} P<0.001$; ns, statistically not significant as calculated using unpaired Student's $t$ test. (D) Proposed model of the plasticity of CTL responses to antigen encounters and how the data presented in this paper may relate to human diseases. In the steady state (peripheral blood), armed effector CTLs respond to other T cells presenting cognate antigen by killing the stimulator T cell, but do not secrete IFN- $\gamma$. The effector CTL itself survives and is anergic. In the context of an inflammatory microenvironment (tumor or other inflamed tissue), exogenous IL-2 licenses the effector CTL to become fully activated and it secretes IFN- $\gamma$ in addition to killing targets. IFN- $\gamma$ augments immune responses upregulating antigen processing and presentation as well as promoting the recruitment of leukocytes to the tissue, promoting tumor immunity and autoimmunity seen in paraneoplastic neurologic disease. SFC, spot-forming cells.

not become activated in response to lymphocyte presentation of the antigen. The observation that $\mathrm{T}$ cellmediated antigen presentation regulates CTL function is reminiscent of Jerne's theory of network regulation of immune responses (10). The repertoire of $\mathrm{B}$ and $\mathrm{T}$ cell receptors represents a collection of stochastic DNA VDJ gene rearrangements as well as mutations. These somatic mutations enable the diversity required to counter a nearly infinite possibility of pathogens but also generates $\mathrm{T}$ cell receptors that are neoantigens and therefore risk autoimmunity. Mechanisms downstream from initial immune tolerance checkpoints 
in the bone marrow and thymus are therefore essential to prevent lymphocyte-directed autoimmunity. For example, anti-idiotype antibodies play a role in limiting humoral immune responses (11-15) and regulatory $\mathrm{T}$ cells can be induced in the periphery (16).

The original definition of anergy described $\mathrm{T}$ cells that are unresponsive to antigenic stimulation, and that become responsive when IL-2 is added to culture (17). We do not know of any other previous work evaluating cytotoxic $\mathrm{CD}^{+} \mathrm{T}$ cell responses to $\mathrm{T}$ cell antigens, with the exception of one group that showed that $\mathrm{T}$ cell presentation of the H-Y antigen induces anergy and apoptosis in a noncytotoxic $\mathrm{CD} 8^{+} \mathrm{T}$ cell line (18). Through our efforts to better characterize the clinical phenotype of patients with PCD, we demonstrate that intracellular antigen expression by lymphocytes in vivo induces effector CTL anergy.

Implications for PCD. CTL anergy to lymphocyte antigen expression may be a necessary element of immune homeostasis. In this way, autoimmune disease may be suppressed, including autoimmunity to CDR2, which rarely develops in patients with breast or ovarian cancer, despite the fact that $22 \%-56 \%$ of these tumors express CDR2 (6). Lymphocyte expression and CDR2 tolerance may therefore help explain the low incidence of PCD (19). The vast majority of patients harboring gynecologic tumors expressing CDR2 are likely anergic to CDR2. We demonstrate here that T cell CDR2 expression underlies a particularly high threshold for mounting an immune response to CDR2. The robust tolerance to this antigen may make it a difficult tumor rejection antigen in vivo. Tumor antigens that are not expressed in $\mathrm{T}$ cells, and do not tolerize, are likely to be more effective targets for tumor vaccines.

Levels of tolerance to PND-associated antigens appear to vary depending on the antigen and its sites of expression. The high degree of tolerance to CDR2 appears to differ from that of other PND antigens such as Nova (the target antigen in paraneoplastic opsoclonus myoclonus ataxia) and HuD (the target antigen in the $\mathrm{Hu}$ syndrome). $\mathrm{HuD}$ and Nova expression are highly restricted to neurons, and effective priming of a high-affinity $\mathrm{T}$ cell population specific to the $\mathrm{HuD}$ antigen can be detected after in vitro stimulation $(20,21)$. This differs from CDR2-specific $\mathrm{T}$ cell responses, which cannot be detected in vivo, or after ex vivo stimulation in a Cdr2-WT mouse.

The finding that $\mathrm{T}$ cell clones produce less IFN- $\gamma$ in response to CDR2 peptide-pulsed T cells than KECs (Figure 5B) is consistent with the clinical observation that patients with PCD and CDR2-specific autoimmunity (high-titer antibodies and cytotoxic $\mathrm{CD}^{+} \mathrm{T}$ cells capable of targeting CDR2-expressing cells [other than $\mathrm{T}$ cells]) do not suffer from autoimmune targeting of $\mathrm{T}$ cells or lymphopenia $(1,2)$. The discrepancy between the active immune clearing of CDR2-expressing Purkinje cells in the CNS and the lack of targeting lymphocytes in the circulation of patients with established PCD indicates that the local microenvironment is a critical component of CTL activation. Local inflammatory mediators, such as IL-2 and possibly others, in the tumor and CNS likely account for the distinct immune outcomes of CDR2specific CTL interactions in CNS, tumor, and blood. A model of how the data presented in this manuscript may relate to human disease is presented in Figure 6D. Considering most of the data presented here describe in vitro experiments, further experiments in vivo are needed to refine a more definitive model.

Implications for lymphotrophic viruses. We also demonstrate that effector CTL anergy in response to lymphocyte-derived antigen is a more broadly relevant phenomenon, as we find the observations regarding CTL anergy extend to lymphocytes presenting viral flu antigens. T cell antigen presentation of flu peptide fails to activate effector CTL IFN- $\gamma$ production (Figure 6). Defective IFN- $\gamma$ production by CTLs leads to defective viral clearance $(22,23)$ likely because an orchestrated immune response is required for clearance and IFN- $\gamma$ production is important for recruitment of other innate effector immune cells. We show that addition of IL-2 rescues T cell IFN- $\gamma$ activation, which defines an anergic phenotype. The discovery that antigen presentation by $\mathrm{T}$ cells induces anergy in effector cytotoxic $\mathrm{T}$ cells is of particular clinical relevance as it suggests that viruses that infect lymphocytes, such as HIV, may preferentially inhabit a lymphocyte niche because it is a relatively immune-privileged site. CD4 ${ }^{+}$ T cell reservoirs of HIV are a major obstacle to HIV eradication (24). A small percentage of people infected with HIV maintain a $\mathrm{CD}^{+} \mathrm{T}$ cell count greater than 500 without antiretroviral therapy and are referred to as elite controllers. CTL activation is a correlate of HIV elite control (25) and may be essential for successful eradication (26). $\mathrm{CD}^{+} \mathrm{T}$ cells derived from elite controllers kill autologous $\mathrm{CD}^{+} \mathrm{T}$ cells in which latent HIV-1 infection has been reversed. In contrast, CD $8^{+} \mathrm{T}$ cells from patients maintained on chronic highly active antiretroviral therapy (HAART) do not produce IFN- $\gamma$ ex vivo. Usual (non-elite controller), chronically HIV-infected patient-derived CD8 ${ }^{+} \mathrm{T}$ cells required prestimu- 
lation with IL-2 and HIV-derived (gag) peptides to overcome functional defects in order to proliferate and become activated in response to HIV-infected T cells (26). Future efforts to overcome effector CTL anergy to antigen expressed in lymphocytes may help overcome this challenge.

\section{Methods}

Generation of Cdr2-KO mice. The Cdr2 targeting vector consisted of Cdr2 intron 1 and the beginning of exon 2, EGFP, the human GAPDH gene, a neomycin resistance cassette flanked by loxP sites, and the Cdr2 3'UTR and 3' flanking sequence. The vector was electroporated into embryonic stem (ES) cells. Neomycin-resistant lines were expanded and recombination was confirmed using long-range PCR. An ES cell line with the desired genomic structure was injected into blastocysts, resulting in male chimeras. For the FLP recombination, chimeras were bred with 129S4/SvJaeSor-Gt(ROSA)26Sorm1(FLPI)Dym/J mice (The Jackson Laboratory, strain 003946) to excise the GAPDH and NEO cassette. Resulting mice were backcrossed for 13 generations to C57BL/6 mice (The Jackson Laboratory). The colony was maintained by breeding heterozygotes. Both $C d r 2-\mathrm{KO}$ and control WT mice were obtained from this breeding strategy. All mice were housed in pathogen-free facilities at Rockefeller University.

Northern blot. Total RNA from mouse cerebellum was prepared by TRIzol (Invitrogen) extraction and column purification using a High Pure RNA Isolation Kit (Roche). Total RNA (10 $\mu$ g per lane) was separated with $0.8 \%$ SeaKem Gold agarose (Lonza) along with Millennium RNA Markers (Ambion). The gel was treated with $0.05 \mathrm{M} \mathrm{NaOH}$ and $1.5 \mathrm{M} \mathrm{NaCl}$ for 20 minutes, and then with $0.5 \mathrm{M}$ Tris, pH 7.5 containing $1.5 \mathrm{M} \mathrm{NaCl}$ for 10 minutes, before being equilibrated for blotting in $20 \times \mathrm{SSC}$ for 20 minutes. The gel was blotted onto a Hybond-N filter (Amersham). Probes were prepared using a Prime-It II Random Primer Labeling Kit (Agilent) with $\left[\alpha-{ }^{32} \mathrm{P}\right] \mathrm{dCTP}$. For hybridization, labeled probes were used at $1 \times 10^{6} \mathrm{cpm} / \mathrm{ml}$ of hybridization solution ( $1 \% \mathrm{BSA}$ fraction $\mathrm{V}, 7 \% \mathrm{SDS}, 0.5 \mathrm{M} \mathrm{NaH}_{2} \mathrm{PO}_{4}$, $\mathrm{pH} 7,1 \mathrm{mM}$ EDTA, $\mathrm{pH} 8$ ). The filter was hybridized overnight at $65^{\circ} \mathrm{C}$ and washed with $2 \times \mathrm{SSC}$ with $0.05 \%$ SDS at $60^{\circ} \mathrm{C} 2$ times for 10 minutes each, and then with $0.1 \times$ SSC with $0.1 \%$ SDS at $60^{\circ} \mathrm{C} 2$ times for 30 minutes each.

IP Western blot. PCD patient antibodies were purified from serum by column chromatography with a 1:1 mixture of protein A and protein G (Invitrogen) (27). Purified PCD patient antibodies were then conjugated to M-270 Epoxy Dynabeads (Invitrogen). Conjugation was performed using the method described by Cristea and Chait (28).

Cerebella from WT mice and Cdr2-KO littermates were homogenized in $1 \times$ PBS with 1\% NP-40, $0.5 \% \mathrm{Na}$ deoxycholate, $0.1 \% \mathrm{SDS}, 20 \mathrm{mM} \mathrm{N}$-ethylmaleimide, and Complete EDTA-free protease inhibitors (Roche). Protein concentrations were adjusted to $6 \mathrm{mg} / \mathrm{ml}$ and proteins were used as input for each IP reaction with $6 \mathrm{mg}$ of PCD antibody-conjugated Dynabeads. After a 30-minute immunoprecipitation at $4^{\circ} \mathrm{C}$, beads were washed once with lysis buffer, and then 4 times with $1 \times \mathrm{PBS} / 0.5 \%$ NP- 40 . Captured proteins were then eluted with $0.5 \mathrm{M} \mathrm{NH}_{4} \mathrm{OH} / 0.5 \mathrm{mM}$ EDTA. Eluates were frozen in liquid nitrogen and then dried completely in a SpeedVac. These eluates were then analyzed by Western blotting using affinity-purified chicken antibodies directed against the CDR2 peptide RKPLKRSSSET, corresponding to amino acids 302-312.

Peptides, antibodies, and mice. CDR2 p120 (CLQTNIDHL), CDR2 p151 (EKPAPSFSCL), CDR2 p285 (PSQSLLEEM), CDR2 p348 (VDTQYSAL), OVA p257 (SIINFEKL), CDR2 p18 (DEPWYDHRDLQQDLQLA), CDR2 p64 (QEIEYLTKQVELLRQMN), CDR2 p170 (LRQHFVYDHVFAEKITS), CDR2 p172 (QHFVYDHVFAEKITSLQ), CDR2 p242 (ATDAYRARALELEAEVA), CDR2 p352 (VDTQYSALKVKYEELLK), $\beta$-gal p726 (NLSVTLPAASHAIPH), $\beta$-gal p96 (DAPIYTNV), A/PR/8 NP p366 (ASNENMETM), and OVA p323 (ISQAVHAAHAEINEAGR) were HPLC purified. Peptides for CDR2 (>95\% pure) were obtained from Life Technologies and all other peptides were from American Peptide, Inc. All antibodies used in the analysis of cells by FACS were obtained from BD Pharmingen; antibodies used in ELISPOTs were from Mabtech. The Cdr2-KO colony was maintained by breeding heterozygotes. Both $C d r 2-\mathrm{KO}$ and control WT mice were obtained from this

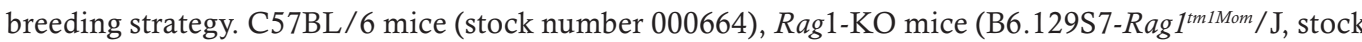
number 002216), and CD45.1 mice (B6.SJL-Ptprc ${ }^{a} P e p c^{b}$ /BoyJ, stock number 002014) were purchased from The Jackson Laboratory. CD45.1 Rag1-KO mice were bred for bone marrow transplantation studies. In all experiments, mice were 6-8 weeks old and housed in pathogen-free facilities at Rockefeller University. 
CDR2 inclusion bodies. The full-length coding sequence of mouse Cdr2 was ligated into the bacterial expression vector $\mathrm{pET}$-28c (EMD Millipore) to create pET28-CDR2. This plasmid was transformed into Rosetta 2 (DE3) (EMD Millipore) competent cells and the resulting cells were plated on LB plates with kanamycin and chloramphenicol. After overnight growth at $30^{\circ} \mathrm{C}$, a single colony was used to inoculate an overnight starter culture. For protein production, the starter culture was grown to an OD600 of 0.6 and cells were induced with $0.4 \mathrm{mM}$ IPTG and grown for another 40 minutes. Cells were harvested by centrifugation and the cell pellet was frozen in a dry ice/ethanol bath. The CDR2 protein present in these cells as inclusion bodies was purified using BugBuster Master Mix (EMD Millipore) according to the manufacturer's protocol. The purified CDR2 inclusion bodies were resuspended in PBS by sonication. Integrity of the protein was verified by SDS-PAGE analysis and the protein concentration was estimated by comparison to a BSA standard curve.

Generation of antibody in mice. Incomplete Freund's Adjuvant (Difco) was reconstituted with $5 \mathrm{mg} / \mathrm{ml}$ Mycobacterium tuberculosis (Difco) to make Complete Freund's adjuvant (CFA). A 1:1 emulsion was made by mixing $10 \mathrm{mg} / \mathrm{ml} \beta$-gal protein (Roche) or $5 \mathrm{mg} / \mathrm{ml} \mathrm{CDR2}$ derived from bacterial inclusion bodies and CFA. Each mouse received $4 \times 50 \mu$ emulsate in their lower back and pertussis toxin on days 0 and 2. Mice were bled and tested for antibody reactivity using in vitro translated/transcribed (TNT Quick Coupled Transcription/Translation Rabbit Reticulocyte Lysate system [T7 promotor version, Promega]) CDR2 and $\beta$-gal 21 days after immunization.

Cell lines and influenza virus. The RMA-S cell line was obtained from Stanley Nathenson (Albert Einstein College of Medicine, Bronx, New York, USA). KECs were obtained by organ culture for 5 days in DMEM with $10 \%$ FCS (GIBCO). Adherent cells were given recombinant murine IFN- $\gamma(50 \mathrm{ng} / \mathrm{ml}, \mathrm{R} \& \mathrm{D}$ Systems) for 48 hours prior to use in assays. Human influenza A/PR/8 virus in allantoic fluid was obtained from Charles River Laboratories. HeLa cells were obtained from the American Type Culture Collection.

Immunization of mice with $A d V-C D R 2$, AdV- $\beta$-gal, or $A d V$-Trk. Serum-free viruses were obtained from Puresyn, Inc. The virus was provided at a concentration of $10^{9}$ particles $/ \mathrm{ml}$. Virus $(100 \mu \mathrm{l})$ was injected intradermally. Pertussis toxin (PTx, Sigma-Aldrich) 400 ng was injected i.p. in each mouse on day 0 and day 2.

Bone marrow chimeras. Host mice were lethally irradiated with a cumulative dose of $900 \mathrm{cGy}(2 \times 450$ cGy). Four hours after the last irradiation, host mice were reconstituted with a total of $10 \times 10^{6}$ bone marrow cells (Thy $1.2^{+}$cells depleted). Mixed bone marrow chimeras were generated using $5 \times 10^{6}$ cells from each donor bone marrow. Seventy to 95 days after reconstitution, 50:50 reconstituted mice were injected with $100 \mu$ purified AdV-CDR2 ( $10^{9}$ particles/ml) intradermally and were treated with PTx (400 ng/ mouse) i.p. on days 0 and 2. Thirteen days later, $\mathrm{CD} 8^{+}$cells were isolated from the spleens and $\mathrm{CD}^{+}$cells were assayed in a 40-hour IFN- $\gamma$ ELISPOT.

$T$ cell isolation and ELISPOT Assay. $\mathrm{CD}^{+}$and $\mathrm{CD}^{+} \mathrm{T}$ cells were isolated by positive selection using MACS beads (Miltenyi Biotec). ELISPOT assays were performed as previously described (29). Briefly, 200,000 isolated $\mathrm{CD}^{+}$or CD8 ${ }^{+} \mathrm{T}$ cells were plated respectively with 250,000 irradiated Thy1.2-depleted splenocytes or 10,000 RMA-S cells pulsed with $1 \mu \mathrm{M}$ peptide per well of a 96-well ELISPOT plate (previously coated with anti-IFN- $\gamma$ antibody and blocked) for 48 hours. IFN- $\gamma$ production by individual cells was detected using a Vectastain Elite Kit and a substrate. ELISPOT plate evaluation was performed in a blinded fashion by Zellnet Consulting using an automated ELISPOT reader (Zeiss) and KS ELISPOT 4.8 software.

Patient samples. Patients positive for the presence of Yo antibodies (PCD) were enrolled in this Rockefeller University IRB-approved study at The Rockefeller University Hospital (RDA-572). All patients gave written consent. PCD patients and healthy controls were leukapheresed and $\mathrm{CD}^{+} \mathrm{T}$ cells were isolated from peripheral blood mononuclear cells by positive selection using MACS beads (Miltenyi Biotec).

Western blot of $\mathrm{CD}^{+} \mathrm{T}$ cells from $\mathrm{PCD}$ patients and healthy donors. Pelleted $\mathrm{CD} 4^{+} \mathrm{T}$ cells were lysed using $5 \times$ Passive Lysis Buffer (Promega) supplemented with Complete Mini, EDTA-free protease inhibitors (Roche) and protein concentration was determined using a BCA Protein Assay kit (Pierce). For each sample, $37 \mu \mathrm{g}$ of total protein from CD4 ${ }^{+} \mathrm{T}$ cells was resolved by $10 \%$ SDS-PAGE and transferred to a PVDF membrane. Membranes were first probed with anti-CDR2 rabbit monoclonal antibody diluted 1:1,000 (clone EPR9464, Abcam), stripped, and reprobed with PND patient serum 1:10,000, and then stripped and incubated with normal serum diluted 1:10,000, and finally stripped and reprobed with anti-GAPDH diluted 1:20,000 (clone 6C5, Life Technologies). HRP-conjugated secondary antibodies diluted 1:10,000 (The Jackson Laboratory) and ECL (PerkinElmer) were used to detect membrane-bound antibodies. 
qPCR. mRNA was isolated using a HiPure kit (Roche). First-strand cDNA synthesis of total RNA was performed with iScript (Bio-Rad). Primer pairs used to detect gene expression in human tissue were CDR2F, 5'-CGTCACAGCAAGGGAACTGGAA-3' and CDR2R, 5'-CACTTGGCTCTGGAGGTGATCA-3'; CDR3F, 5'-CAGGACCTGGAGCAGGACT-3' and CDR3R, 5'-ACCTGTTCCTCATTGGTGGA-3'; HRP14F, 5'-CGGAGCTGACCAGACTTTTC-3' and HRP14R, 5'-GGTTCGACCGTCATACTTCTTC-3'.

CDR2 T cell clone. The CDR2-120-specific T cell clone was generated by immunizing Cdr2-KO mice with AdV-CDR2. After in vitro stimulation, $\mathrm{CD}^{+} \mathrm{T}$ cells were isolated and cloned by limited dilution. A high-affinity clone was selected by screening for responses to greater than $10^{-9} \mathrm{M}$ CDR2-120 peptidepulsed RMA-S cells. The clone was assayed and restimulated weekly with 10-9 $\mathrm{M}$ CDR2-120 peptidepulsed irradiated splenocytes and $10 \mathrm{U} / \mathrm{ml} \mathrm{rhIL}-2$ (Chiron).

$D C s$. Bone marrow-derived DCs were generated as previously described (30). Briefly, bone marrow was isolated from Cdr2-KO mice and cultured for 6 days in 10\% supernatant from GM-CSF-transfected J558L cells. On day 6, Cdr2-KO DC cultures were harvested and cultured in the presence of GM-CSF and $80 \mathrm{ng} / \mathrm{ml}$ recombinant mouse TNF- $\alpha$ (R\&D Systems) was added as a maturation stimulus. Forty-eight hours later, $\mathrm{CD} 11^{+}$cells were isolated and used as stimulators in the ELISPOT.

In vivo transfer of antigen-pulsed $C D 8^{+} T$ cells. C57BL/ 6 mice were simultaneously given 300 hemagglutination units (HAU) A/PR/8 virus i.p. and $5 \times 10^{6} \mathrm{NP}$-pulsed and 3-times-washed CD45.1 CD8 ${ }^{+}$ T cells intravenously. On day $8,100 \mu 1$ of blood was red blood cell lysed with ACK (GIBCO) and then coincubated with NP-D ${ }^{\text {b-tetramer }}(\mathrm{MBL}), \mathrm{CD} 45.2$ (clone 104), and CD8a (clone 53-6.7) for $30 \mathrm{~min}$ utes at $6^{\circ} \mathrm{C}$. Dead cells were excluded using TO-PRO-3 (Thermo Fisher Scientific) and immediately acquired by FACS.

Generation of NP-specific effector CTLs. C57BL/6 were immunized with $300 \mathrm{HAU}$ of A/PR/8 virus i.p. Fifteen days after immunization, spleens were harvested and $5 \times 10^{6} \mathrm{cells} / \mathrm{ml}$ were stimulation with $1 \mu \mathrm{M}$ NP-specific peptide. On day 5 of NP peptide stimulation, CD8 ${ }^{+}$cells were isolated using MACs positive selection (Miltenyi Biotec). Where indicated, $20 \mathrm{U} / \mathrm{ml}$ of rhIL-2 (Chiron) was added to the assay.

Statistics. Data were analyzed using Prism software (GraphPad). Standard deviations are reported for ELISPOT data and unpaired Student's $t$ test (2-tailed) was used to compare 2 groups. A $P$ value of less than 0.05 was considered significant.

Study approval. The present studies in humans were IRB approved at The Rockefeller University Hospital (RDA-572). All patients gave written informed consent. Animal procedures were performed in compliance and were approved by The Rockefeller University Institutional Animal Care and Use Committee regulations at The Rockefeller University.

\section{Author contributions}

NEB, DEO, ECG, BDS, GCC, and RBD conceived the study. NEB and GCC were responsible for the methodology. NEB, DEO, ECG, BDS, GCC, TRM, JF, KJO, ZR, SP, and MOF carried out the investigation. NEB and DEO wrote the original draft of the manuscript. NEB, DEO, ECG, BDS, GCC, TRM, JF, KJO, ZR, SP, MOF, MJM, and RBD reviewed and edited the manuscript. RBD acquired funding.

\section{Acknowledgments}

We would like to thank the patients with PCD and their families, for their participation in research as well as the staff of the Rockefeller University Hospital and grant UL1 TR000043 from the National Center for Advancing Translational Sciences (NCATS), NIH Clinical and Translational Science Award (CTSA) program. This work was also supported by the NIH grant R01 NS034389. We would like to thank the Rockefeller Gene Targeting Facility for generating the ES cells resulting in the generation of the mice incorporating the targeted $C d r 2$ gene KO. RBD is an Investigator of the Howard Hughes Medical Institute (HHMI). GCC was supported by an HHMI Predoctoral Fellowship.

Address correspondence to: Robert B. Darnell, Box 226, The Rockefeller University, 1230 York Avenue, New York, New York 10065, USA. Phone: 212.327.7474; Email: darnelr@rockefeller.edu. 
1. Albert ML, Austin LM, Darnell RB. Detection and treatment of activated T cells in the cerebrospinal fluid of patients with paraneoplastic cerebellar degeneration. Ann Neurol. 2000;47(1):9-17.

2. Albert ML, Darnell JC, Bender A, Francisco LM, Bhardwaj N, Darnell RB. Tumor-specific killer cells in paraneoplastic cerebellar degeneration. Nat Med. 1998;4(11):1321-1324.

3. Darnell RB. Paraneoplastic neurologic disorders: windows into neuronal function and tumor immunity. Arch Neurol. 2004;61(1):30-32.

4. Santomasso BD, et al. A T-cell receptor associated with naturally occurring human tumor immunity. Proc Natl Acad Sci USA 2007;104(48):19073-19078.

5. Darnell RB, Posner JB. Paraneoplastic syndromes involving the nervous system. N Engl J Med. 2003;349(16):1543-1554.

6. Darnell JC, Albert ML, Darnell RB. Cdr2, a target antigen of naturally occuring human tumor immunity, is widely expressed in gynecological tumors. Cancer Res. 2000;60(8):2136-2139.

7. Pittock SJ, Kryzer TJ, Lennon VA. Paraneoplastic antibodies coexist and predict cancer, not neurological syndrome. Ann Neurol. 2004;56(5):715-719.

8. Orange D, et al. Cellular immune suppression in paraneoplastic neurologic syndromes targeting intracellular antigens. Arch Neurol. 2012;69(9):1132-1140.

9. Johnson AJ, Upshaw J, Pavelko KD, Rodriguez M, Pease LR. Preservation of motor function by inhibition of CD8 ${ }^{+}$virus peptide-specific T cells in Theiler's virus infection. FASEB J. 2001;15(14):2760-2762.

10. Jerne NK. Towards a network theory of the immune system. Ann Immunol (Paris). 1974;125C(1-2):373-389.

11. Larsson HE, et al. Decline in titers of anti-idiotypic antibodies specific to autoantibodies to GAD65 (GAD65Ab) precedes development of GAD65Ab and type 1 diabetes. PLOS ONE. 2013;8(6):e65173.

12. Oak S, et al. The lack of anti-idiotypic antibodies, not the presence of the corresponding autoantibodies to glutamate decarboxylase, defines type 1 diabetes. Proc Natl Acad Sci USA. 2008;105(14):5471-5476.

13. Cosenza H, Köhler H. Specific suppression of the antibody response by antibodies to receptors. Proc Natl Acad Sci USA. 1972;69(9):2701-2705

14. Cosenza H, Köhler H. Specific inhibition of plaque formation to phosphorylcholine by antibody against antibody. Science. 1972;176(4038):1027-1029.

15. Rodkey LS. Studies of idiotypic antibodies. Production and characterization of autoantiidiotypic antisera. J Exp Med. 1974;139(3):712-720.

16. Sakaguchi S, Wing K, Onishi Y, Prieto-Martin P, Yamaguchi T. Regulatory T cells: how do they suppress immune responses? Int Immunol. 2009;21(10):1105-1111.

17. Jenkins MK, Pardoll DM, Mizuguchi J, Quill H, Schwartz RH. T-cell unresponsiveness in vivo and in vitro: fine specificity of induction and molecular characterization of the unresponsive state. Immunol Rev. 1987;95:113-135.

18. Chai JG, Bartok I, Scott D, Dyson J, Lechler R. T:T antigen presentation by activated murine CD $8^{+} \mathrm{T}$ cells induces anergy and apoptosis. J Immunol. 1998;160(8):3655-3665.

19. Posner JB, Darnell RB, Posner JB. Paraneoplastic Syndromes. New York, NY: Oxford University Press; 2011.

20. DeLuca I, Blachère NE, Santomasso B, Darnell RB. Tolerance to the neuron-specific paraneoplastic HuD antigen. PLoS ONE. 2009;4(6):e5739.

21. Blachère NE, et al. T cells targeting a neuronal paraneoplastic antigen mediate tumor rejection and trigger CNS autoimmunity with humoral activation. Eur J Immunol. 2014;44(11):3240-3251.

22. Huang S, et al. Immune response in mice that lack the interferon-gamma receptor. Science. 1993;259(5102):1742-1745

23. Lu B, et al. Targeted disruption of the interferon-gamma receptor 2 gene results in severe immune defects in mice. Proc Natl Acad Sci USA. 1998;95(14):8233-8238.

24. Chun TW, Moir S, Fauci AS. HIV reservoirs as obstacles and opportunities for an HIV cure. Nat Immunol. 2015;16(6):584-589

25. Hersperger AR, et al. Perforin expression directly ex vivo by HIV-specific CD8 T-cells is a correlate of HIV elite control. PLoS Pathog. 2010;6(5):e1000917.

26. Shan L, et al. Stimulation of HIV-1-specific cytolytic T lymphocytes facilitates elimination of latent viral reservoir after virus reactivation. Immunity. 2012;36(3):491-501.

27. Harlow E, Lane D. Immunoaffinity purification: coupling antibodies to protein A or G bead columns. CSH Protoc. 2006;2006(1)

28. Cristea IM, Chait BT. Conjugation of magnetic beads for immunopurification of protein complexes. Cold Spring Harb Protoc 2011;2011(5):pdb.prot5610.

29. Blachère NE, et al. IL-2 is required for the activation of memory CD8+ $\mathrm{T}$ cells via antigen cross-presentation. J Immunol. 2006;176(12):7288-7300.

30. Inaba K, et al. Generation of large numbers of dendritic cells from mouse bone marrow cultures supplemented with granulocyte/macrophage colony-stimulating factor. J Exp Med. 1992;176(6):1693-1702. 